\title{
Microrganismo endofíticos para conservação de produtos hortícolas
}

\author{
Endophytic microorganisms for the preservation of vegetables \\ Microorganismo endofíticos para la conservación de productos hortícolas
}

Marcos Fabian Sanabria Franco ORCID: https://orcid.org/0000-0002-7820-9037

Universidade de São Paulo, Brasil

E-mail: marcosfabiansanabria@gmail.com

Angelo Pedro Jacomino

ORCID: https://orcid.org/0000-0003-0863-6698

Universidade de São Paulo, Brasil

E-mail: jacomino@usp.br

Poliana Cristina Spricigo

ORCID: https://orcid.org/0000-0002-8262-4858

Universidade de São Paulo, Brasil

E-mail: polianaspricigo@usp.br

Diana Gissell Barreto Ramos

ORCID: https://orcid.org/0000-0001-7299-1366

Universidade Federal Rural de Pernambuco, Brasil

E-mail: dianabarretoramos@hotmail.com

Juliana Elias de Oliveira

ORCID: https://orcid.org/0000-0003-4866-6939 Universidade de São Paulo, Brasil

E-mail: julianaeo@usp.br

Mariana Trevisan Florêncio

ORCID: https://orcid.org/ 0000-0003-2537-5688

Universidade de São Paulo, Brasil

E-mail: mariana.florencio@usp.br

Marcelo Almeida de Oliveira Junior

ORCID: https://orcid.org/0000-0002-1027-2777

Universidade de São Paulo, Brasil

E-mail: marcelo_oli@usp.br

Rodrigo José Milan

ORCID: https://orcid.org/0000-0003-0216-0270

Universidade de São Paulo, Brasil

E-mail: milan.rodrigo@usp.br

Ricardo Alfredo Kluge

ORCID: https://orcid.org/0000-0002-6198-8871

Universidade de São Paulo, Brasil

E-mail: rakluge@usp.br

\begin{abstract}
Resumo
A perda de alimento de frutas e hortaliças causadas por doenças pós-colheita é um grande problema no mundo. Dentro da planta, acontecem vários fenômenos referentes às atividades endófitos microbianas, começando desde a estimulação direta do crescimento da planta pela ação de fitohormônios ou pela produção de metabólitos como mecanismo de defesa no vegetal. Conhecer a comunidade microbiana auxilia no manejo de prevenção de distúrbios fisiológicos e doenças após-colheita. Mediante a revisão das literaturas, foram observados os mecanismos de biocontrole de microrganismos, a ação da maioria dos patógenos mais comuns, os gêneros de microrganismos de interesse comercial e a perspectiva de microrganismos endofíticos para o futuro na pós-colheita de frutas e hortaliças. Conclui-se que a demanda global por alimentos mais saudáveis está em auge, pelo o controle de doenças através de microrganismo endofíticos é uma realidade na pós-colheita e é um desafio para as próximas pesquisas na obtenção de maiores benefícios ecológico.
\end{abstract}

Palavras-chave: Microrganismo endófito; Biocontrole; Defesa; Pós-colheita.

\section{Abstract}

The loss of fruit and vegetable food caused by post-harvest diseases is a major problem in the world. Inside the plant, several phenomena related to microbial endophyte activities occur, starting from the direct stimulation of the plant's growth by the action of phytohormones or by the production of metabolites as a defense mechanism in the plant. Knowing the microbial community helps in managing the prevention of physiological disorders and post-harvest diseases. By reviewing the literature, the mechanisms of biocontrol of microorganisms, the action of most common 
pathogens, the genera of microorganisms of commercial interest, and the prospect of endophytic microorganisms for the future in the fruit and vegetable postharvest were observed. It is concluded that the global demand for healthier foods is on the rise, as disease control through endophytic microorganisms is a reality in the post-harvest period and is a challenge for future research to obtain greater ecological benefits.

Keywords: Endophyte microorganism; Biocontrol; Defense; Post-harvest.

\section{Resumen}

La pérdida de alimentos de frutas y verduras ocasionada por enfermedades pos-cosecha genera problemas importantes en el mundo. Dentro de la planta, existen varios fenómenos relacionados con las actividades endófitas microbianas, comenzando por la estimulación directa del crecimiento vegetal por la acción de las fitohormonas o por la producción de metabolitos como mecanismo de defensa en la planta. Conocer la comunidad microbiana ayuda en el manejo de la prevención de trastornos fisiológicos y enfermedades pos-cosecha. Mediante la revisión de la literatura se observaron los mecanismos de biocontrol de los microorganismos, la acción de la mayoría de los patógenos más comunes, los géneros de microorganismos de interés comercial y la perspectiva de los microorganismos endófitos a futuro en la pos-cosecha de frutas y hortalizas. Se concluye que la demanda mundial por alimentos más saludables va en aumento, debido a eso el control de enfermedades a través de microorganismos endófitos ya es una realidad en la pos-cosecha y es un desafío para futuras investigaciones para obtener mayores beneficios ecológicos.

Palabras clave: Microorganismo endófito; Biocontrol; Defensa; Poscosecha.

\section{Introdução}

Os microrganismos endofíticos são encontrados praticamente em todas as plantas da Terra, residem nos tecidos vivos da planta hospedeira e possuem uma variedade de relações que vão de simbióticas a patogênicas. Os endófitos podem contribuir para sua planta hospedeira com diversos metabólitos, tanto primários como secundários para o controle biológico de inúmeras doenças e como promotores de crescimento vegetal (Strobel et al., 2004; Santos \& Varavallo, 2011; Polli et al., 2012).

Durante a infecção endofítica os metabólitos específicos de plantas são ativados, desempenhando um papel significativo na colonização e na instauração de interações endofíticas. Essas substâncias não apenas desempenham um papel na defesa e competição, mas também pode ser necessária para interação específica com o endófito (Kharwar et al., 2020). Dentro da planta, essas bactérias exercem vários benéficos, incluindo a estimulação direta do crescimento da planta. Além disso, os endófitos bacterianos protegem seu hospedeiro vegetal por meio de patógenos de biocontrole ou induzindo o sistema imunológico inato da planta (Morales-Cedeño et al., 2020).

O interesse de encontrar novos medicamentos que podem ser candidatos eficazes para o tratamento de doenças recémdesenvolvidas em humanos, plantas e animais é imensa, pelo que os estudos sobre os organismos endofíticos estão em constante avanço (Strobel et al., 2004). A agricultura sustentável procura inovações como o uso de os agentes bacterianos para controlar diversas doenças de plantas (Morales-Cedeño et al., 2020).

A modificação genética de plantas pode ser usada para modular intencionalmente a composição da microbioma e sua função, recrutando antagonistas de doenças e promotores da saúde das plantas que realçam a qualidade dos produtos colhidos. Conhecer os sistemas da comunidade microbiana levará ao desenvolvimento de consórcios naturais ou sintéticos a ser usados para prevenir doenças pós-colheita e mitigar distúrbios fisiológicos nos produtos colhidos (Chaouachi et al., 2021).

A perda de alimento de frutas e vegetais causados por doenças pós-colheita é um grande problema no mundo. Para prevenir e controlar doenças pós-colheita geralmente é utilizado fungicidas químico, mas o uso em longo prazo e em larga escala tornará os patógenos resistentes e potencialmente terá um impacto negativo na saúde humana e no meio ecológico (Huang et al, 2020).

Na pós-colheita, o controle biológico com microrganismos endofíticos para doenças de frutas e vegetais aumento nos últimos 20 anos, isto porque elas têm as vantagens de serem mais ecologicamente corretos, sustentáveis e seguros. No entanto, existem relativamente poucos estudos, sendo que os novos conhecimentos podem ser usados para prevenir doenças pós- 
colheita e mitigar distúrbios fisiológicos nos produtos colhidos (Huang et al., 2021; Droby \& Wisniewski, 2018 ). Nesta revisão pretendesse analisar literaturas com aplicações de microrganismos na conservação de produtos hortícolas após colheita.

\section{Revisão de Literatura}

\subsection{Microrganismos em plantas}

O microbioma de plantas mais estudado é aquele associado na rizosfera das plantas, onde se induz a eficiência nutricional, liberação de compostos antimicrobianos, produção de enzimas, entre outras estratégias de combate ante-estresse. A compressão das populações microbianas ativas e não ativas e sua relação com a saúde e doença das plantas, bem como benefícios de qualidade para os humanos serve como técnica promissora para selecionar as espécies a produzir (Berendsen et al., 2012; Silva et al., 2020; Droby \& Wisniewski, 2018).

São cada vez mais presentes pesquisas com microrganismos endofíticos na procura da sustentabilidade, por isso, nos últimos anos as pesquisas de microrganismos capazes de liberar fósforo $(\mathrm{P})$ a partir de fontes de fósforo de baixa solubilidade, como os fosfatos naturais dos grupos dos endófitos facultativos são opções na nutrição de plantas. Além disso, os microrganismos endofíticos são produtores de diferentes metabolitos, tais como as enzimas hidrolíticas, que apresentam grande aplicabilidade nos processos industriais possuindo alta especificidade e estabilidade, baixo impacto ao meio ambiente, possibilidade de produção em grande escala em curto período de tempo e com baixo custo (Ungaratt et al., 2020; Ribeiro et al., 2015; Miguel et al., 2021).

No caso de bactérias endofíticos, muito estudadas na microbiologia agrícola têm sido encontradas em várias plantas, onde colonizam os tecidos internos do seu hospedeiro. As maiorias desses microrganismos originam das raízes (Silva et al., 2004), entretanto podem ser transmitidos via ferimentos e aberturas naturais, ou penetram ativamente pela produção de enzimas hidrolíticas. Essa relação parece proporcionar outras vantagens, como proteção contra patógenos por indução dos mecanismos de defesa da planta aumento do rendimento das colheitas, fixação do nitrogênio atmosférico além da solubilização e assimilação de fosfato, promovendo o crescimento da planta. Além disso, são utilizadas na remoção de agentes tóxicos do solo (Miguel et al., 2021).

A diversidade do bioma brasileiro é uma grande fonte de estudos de caracterização de substâncias produzidas por microrganismos, com atividade antimicrobiana, que atinge a reduzir significativamente o problema da resistência aos antibióticos (Santos \& Girardello, 2021). Nos últimos anos, houve um auge na demanda por tecnologias sustentáveis, pelo que os estudos de microrganismos aumentaram (tabela 1). Isto, com fins de amortizar os custos de produção, acrescentar a produtividade e a rentabilidade do agronegócio numa agricultura sustentável (Rezende et al., 2021).

Bactérias Burkholderia sp possuem uma ação antagônica na redução do crescimento fúngico (Brito et al., 2018). Atualmente o controle biológico de fitobactérias é muito importante por se tratar de um método natural, sem causar impactos ao ambiente e efeitos toxicológicos (Silva et al., 2008). A imunidade da planta aos patógenos vai depender de diversos mecanismos de proteção, físicos ou moleculares que, em conjunto, vão determinar se uma planta será ou não imune a um patógeno. Estudos da interação beneficiam diretamente no controle de pragas agrícolas, principalmente pela transformação de plantas, que as tornam resistentes aos patógenos bacterianos, fúngicos e virais (Rhoden et al., 2019).

Numa perspectiva biotecnológica futura, os fungos e bactérias endofíticos poderiam modificar-se geneticamente para expressar genes de interesse, como ferramenta que favoreçam o crescimento vegetal, síntese de vitaminas, aminoácidos e metabolitos de interesse para aumentar os níveis de produtividade das culturas num contexto sustentável dos recursos (Peixoto, 2004; Mariano et al., 2004). Esses tipos de mecanismos e medidas alternativas de manejos garante um mercado economicamente viável (Senhor et al., 2009). 
Tabela 1. Doenças e patógenos pós-colheita mais comuns.

\begin{tabular}{|c|c|c|}
\hline FRUTAS & DOENÇA & PATÓGENO \\
\hline \multirow{3}{*}{ Frutas de pomo } & Podridão amarga & Colletotrichium gloesporioides \\
\hline & Coração mofado & Aternaria spp. \\
\hline & Outros mofos & $\begin{array}{l}\text { Penicillium spp. }(\text { mofo azul) } \\
\text { Botrytis cinerea }(\text { mofo cinza) }\end{array}$ \\
\hline \multirow{3}{*}{ Frutas de caroço } & Podridão parda & Monilinia spp. \\
\hline & Podridão de Rhizopus & Rhizopus spp. (R. stolonifer) \\
\hline & Outros mofos & $\begin{array}{l}\text { Penicillium spp. }(\text { mofo azul) } \\
\text { Botrytis cinerea }(\text { mofo cinza) }\end{array}$ \\
\hline \multirow{3}{*}{ Frutos do bosque } & Podridão de Cladosporium & Cladosporium spp. \\
\hline & Podridão de Rhizopus & Rhizopus spp. \\
\hline & Outros mofos & $\begin{array}{l}\text { Penicillium spp. (mofo azul) } \\
\text { Botrytis cinerea (mofo cinza) }\end{array}$ \\
\hline \multirow{4}{*}{ Cítricos } & Melanose em frutos & Diaporthe citri \\
\hline & Aguado & Phytophthora citrophtora \\
\hline & Podridão do pedúnculo & Phomopsis citri \\
\hline & Outros mofos & $\begin{array}{l}\text { Penicillium italicum (mofo azul) } \\
\text { Penicillium digitatum (mofo verde) }\end{array}$ \\
\hline \multirow{2}{*}{ Uva } & Podridão de Rhizopus & Rhizopus spp. \\
\hline & Outros mofos & $\begin{array}{l}\text { Penicillium spp. (mofo azul) } \\
\text { Botrytis cinerea }(\text { mofo cinza) }\end{array}$ \\
\hline \multirow[b]{2}{*}{ Bananas } & Antracnoses & Colletotrichium musae \\
\hline & Podridão da coroa & $\begin{array}{c}\text { Fusarium spp. Verticillium spp. } \\
\text { Acrenomium spp. } \\
\text { Colletotrichium musae }\end{array}$ \\
\hline \multirow{2}{*}{ Abacate } & Antracnoses & $\begin{array}{c}\text { Colletotrichium gloesporoides } \\
\text { Colletotrichium acutatum }\end{array}$ \\
\hline & Podridão mole bacteriana & Erwinia carotova \\
\hline \multirow{3}{*}{ Abacaxi } & Bolha de água & Thielaviopsis paradoxa \\
\hline & Fermentação por leveduras & Saccharomyces spp. \\
\hline & Podridão de botão bacteriano & Erwinia herbicola var. ananas \\
\hline
\end{tabular}

Fonte: Coates e Johnson (1997). Adaptado por Martin Bonilla (2019).

Abdelfattah et al. (2016), analisando maças comprovaram que há uma diversidade alfa e beta da microflora fúngica nas diferentes partes da fruta (Figura 1). Isso indica fortemente que a microflora associada a diferentes porções da fruta da maçã precisa ser considerada ao projetar sistemas de biocontrole para o gerenciamento de doenças após-colheita. Os autores encontraram, além disso, populações diferentes de fungos presentes em frutas obtidas de sistemas orgânicos vs. pomares convencionais, essa presença de vários táxons únicos nos frutos produzidos organicamente está relacionada à prática de manejo.

Num período de armazenamento de duas semanas em temperatura ambiente de maçãs, foi observado que o Penicillium foi dominante nas amostras de casca e Alternaria foi dominante nas amostras de cálice e caule. Entanto, as famílias de fungos os Ascomycotas representaram mais de 90\% das espécies observadas, seguido por Basidiomycota (8\%) e 
Chytridiomycota (0,1\%) (Abdelfattah et al., 2016). Droby e Wisniewski (2018), acreditam que o desenvolvimento desses novos paradigmas nos estudos de microbioma ajudará a melhorar as tecnologias de pós-colheita de frutas.

Cia (2002), ressalta que a incidência de doenças em pós-colheita é influenciada pelas condições climáticas da região produtora, espécies e cultivares, além de tratos culturais e fitossanitários incorretos, como excesso de adubação nitrogenada e uso inadequado ou abusivo de defensivos, acarretando seleção de estirpes resistentes de determinados patógenos na précolheita. Agora na colheita e pós-colheita o transporte, manuseio, tratamento fitossanitário, climatização, destanização, embalagens e armazenamento inadequadas podem comprometer todo o manejo de campo, causando perdas significativas de frutas e grandes prejuízos.

Figura 1. Gêneros de fungos na casca (PE), feridas superficiais $(\mathbf{W})$, extremidade do cálice $(\mathbf{C E})$ e extremidade do caule (SE).

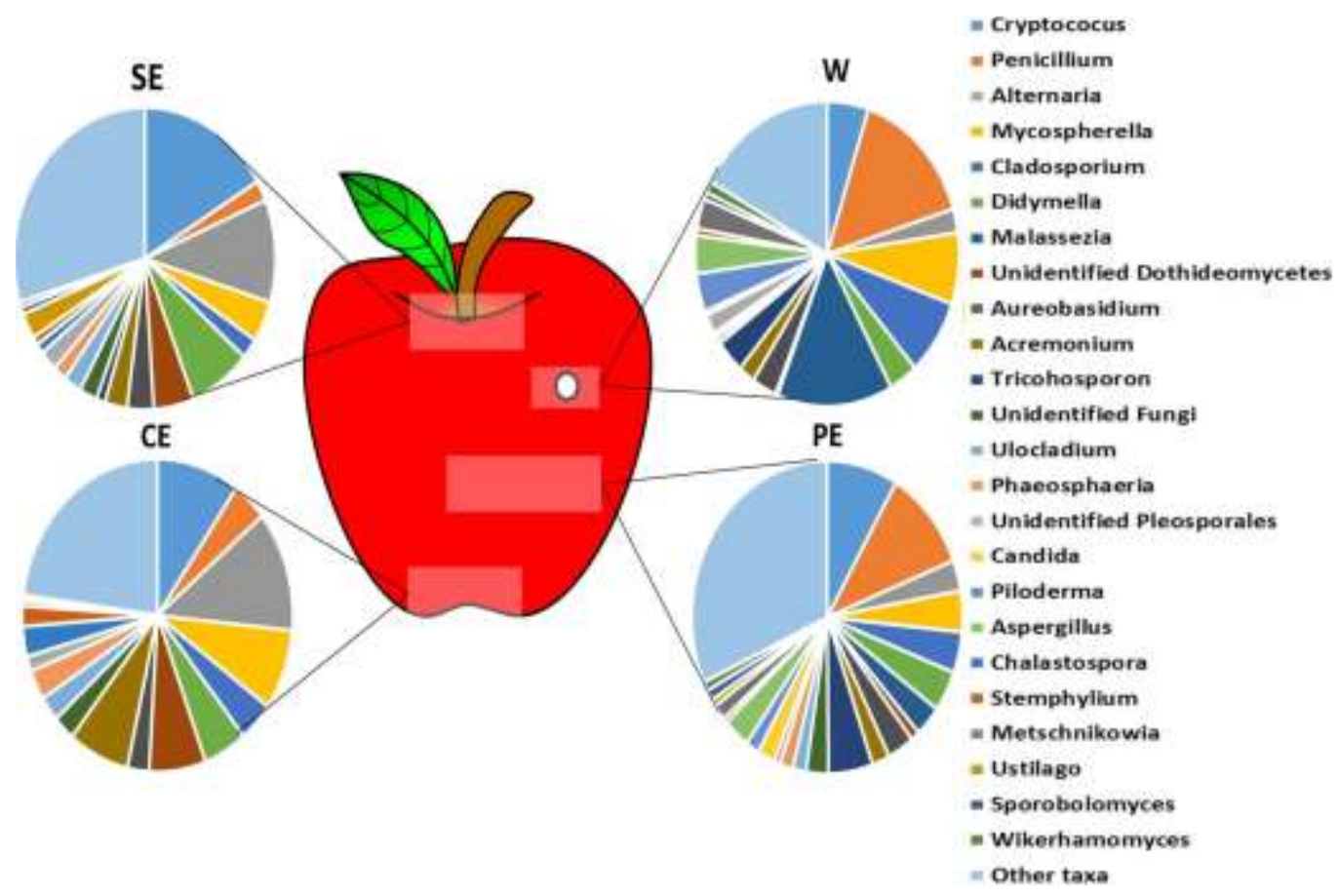

Fonte, Abdelfattah et al. (2016).

\subsection{Microrganismos na pós-colheita de frutas e Hortaliças}

Segundo Droby et al. (2016), os microrganismos são parte integrante da composição de frutas e vegetais e são localizados como epífitas na superfície ou como endófitos nos tecidos. A maioria desses microrganismos não é patogênica, no entanto, seu papel e função na saúde, qualidade e resistência a doenças dos frutos antes e depois da colheita são amplamente desconhecidos ainda. Os mesmos autores também fazem referência da importância de obter informações sobre a ecologia dos microrganismos, isto para o desenvolvimento de vários produtos comerciais de biocontrole.

São necessários métodos alternativos no controle de doenças em frutas ou hortaliças como o uso de agentes de biocontrole. Ainda seu uso é muito limitado, devido à variabilidade dos produtos de biocontrole em sua eficácia, pelo que é se precisa indagar mais sobre a ecologia dos microrganismos utilizados no controle biológico para combater as doenças póscolheita (Liu et al., 2013; Droby et al., 2009; Dobry et al., 2016). Assim, nos últimos anos, o controle biológico na pós-colheita de frutos vem se mostrando como uma alternativa promissora ao controle químico (Figura 2) (Zhimo et al., 2016). 
Figura 2. Mecanismo e aplicação de endófitos na resistência às doenças de frutas e vegetais pós-colheita.

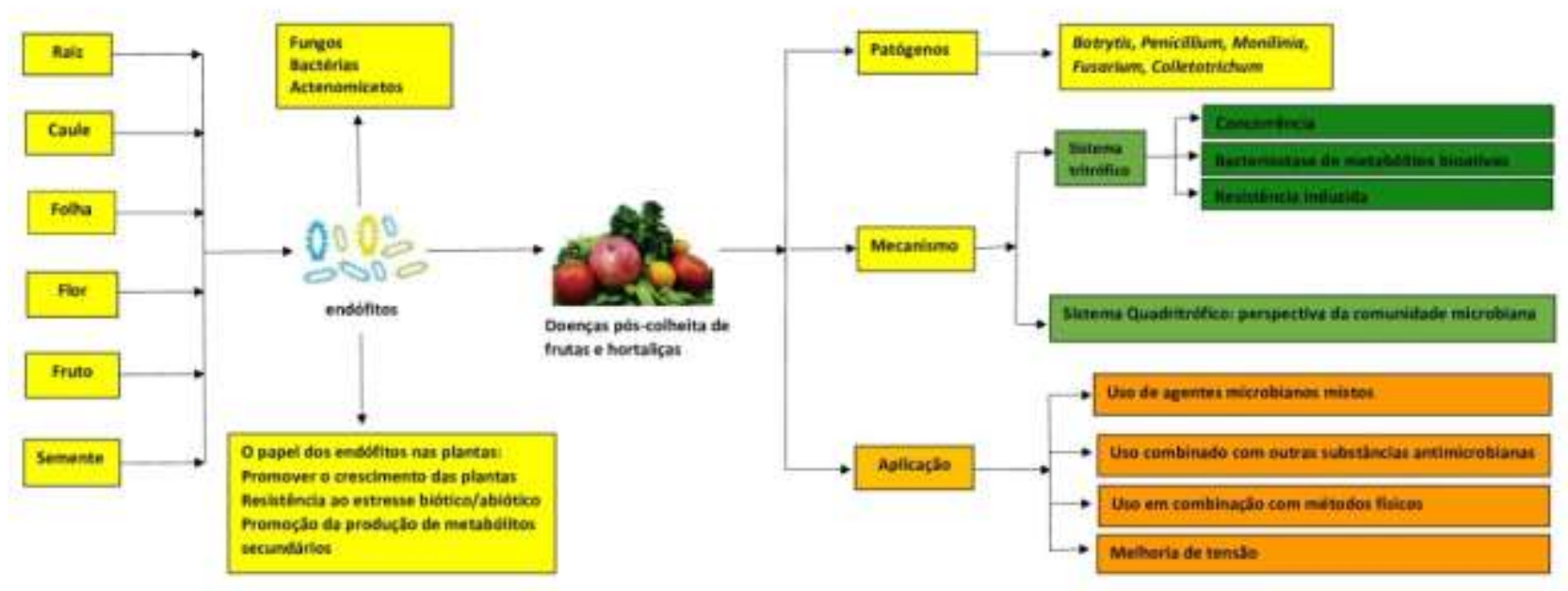

Fonte: Adoptada de Huang et al. (2021).

Numa pesquisa feita por Medina-Romero et al. (2017), concluíram que os COVs selecionados de fungos endofíticos do gênero Hypoxylon apresentam potentes efeitos antifúngicos contra o fitopatógeno Fusarium oxysporum. Os autores ressaltaram que os COVs são candidatos promissores para o desenvolvimento de biopesticidas no tratamento pós-colheita do tomate contra doenças causadas por Fusarium oxysporum já que afeta sua morfologia das hifas e um efeito inibitório na respiração.

O controle biológico é um método alternativo para prevenir a deterioração pós-colheita dos frutos, ela procura diminuir a quantidade de resíduos químicos aplicados nesses alimentos, sendo considerada uma opção ecologicamente mais correta (Martín Bonilla, 2019). Os organismos antagonistas apresentam diferentes mecanismos de ação baseados na interação que estabelecem com o patógeno, o hospedeiro (a fruta neste caso) e sua população microbiana associada. Essa inter-relação é determinada por fatores como temperatura, $\mathrm{pH}$, estresse oxidativo e atividade da água. Em alguns casos, vários mecanismos atuam simultaneamente, dificultando a determinação de qual deles está relacionado a uma ação específica (Spadaro, et al., 2016; Di Francesco et al., 2016).

Assim, como tecnologia de conservação, o uso de Bacillus subtilis imediatamente antes do armazenamento em batatas melhorou algumas propriedades como o conteúdo de ácido ascórbico e diminuiu o acúmulo de prolina induzida por patógenos e a peroxidação lipídica em tubérculos. Isso indica um efeito protetor conferido às células contra o oxigênio reativo e uma extensão dos processos de envelhecimento, manifestado por uma vida útil prolongada e preservação prolongada da aparência fresca (Lastochkina et al., 2020).

Benato (1999), descreve que para a seleção dos antagonistas na pós-colheita deve-se considerar a infecção quiescente e capacidade do patógeno de penetrar a cutícula intacta do hospedeiro seja por os ferimentos ou pelas aberturas naturais. Assim, os antagonistas ideais para seu desenvolvimento comercial devem exibir (Figura 3); uma rápida taxa de crescimento, utilizar nutrientes a baixas concentrações, desenvolver-se na superfície da fruta ou no local de infecção sob condições adversas como, a temperatura, pH ou condições osmóticas desfavoráveis, ser geneticamente estável, não patogênico ao hospedeiro, efetivo a baixas concentrações, amplo espectro de ação, fácil aplicação e não produzir substâncias tóxicas ao homem e serem resistentes aos pesticidas (Droby et al., 2009; Benato, 2002). 
Figura 3. Características ideais de um antagonista para seu desenvolvimento comercial como produto de controle de doenças pós-colheita.

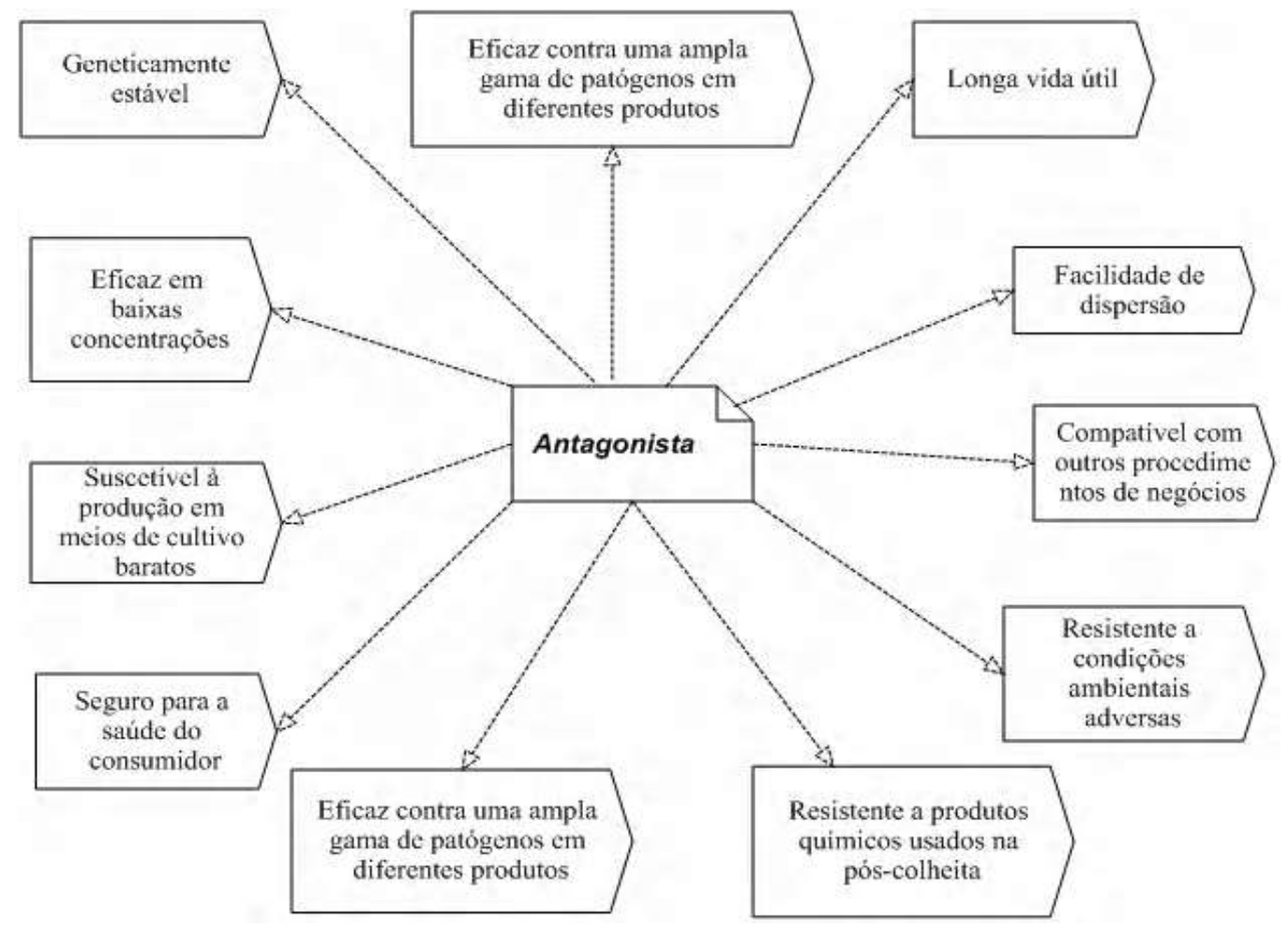

Fonte: Adaptado de Droby et al. (2009).

Konsue et al. (2020), avaliaram os mecanismos antagônicos de leveduras antagônicas em frutas de mangas, notando que essas leveduras antagonistas mostraram a inibição do crescimento do patógeno fúngico in vitro e in vivo. As leveduras antagônicas apresentam diversos mecanismos antagônicos, incluindo a produção de compostos orgânicos voláteis (COVs) e a competição por nutrientes e espaço formação de biofilme e produção de sideróforos. Portanto, essas leveduras antagonistas têm potencial para uso como agentes de controle biológico para o controle da podridão dos frutos e doenças da antracnose. Na tabela 2 são observados alguns exemplos de microrganismos antagônicos utilizados na pós-colheita.

Chaouachi et al. (2021) numa pesquisa avaliaram microrganismos endófitos para prevenir a infecção pós-colheita de tomate com B. cinerea em tomate, por meio da produção de COVs e compostos solúveis. Para isso, fizeram uma coleção de 50 cepas bacterianas obtidas a partir de diferentes órgãos de tomateiros de seis localidades na região de Cape Bon (Tunísia). Apesar da pequena escala geográfica, a complexidade e abundância das comunidades endofíticas variaram muito de acordo com o local de origem.

A pesquisa de Chaouachi et al. (2021), fornece evidências sobre a capacidade de biocontrole mediada por os compostos voláteis para reduzir a decomposição pós-colheita de Botrytis cinerea na pós-colheita de tomate. Os tomateiros saudáveis abrigam diversas cepas de bactérias endofíticas colonizando principalmente folhas e algumas delas emitindo COVs com atividade antifúngica e promotora de crescimento de plantas. A caracterização dos COVs liberados por bactérias mostrou um conjunto básico de compostos produzidos por todas as bactérias selecionadas, e alguns voláteis específicos da cepa, com alguns deles já relatados por suas atividades antifúngicas. 
Tabela 2. Antagonistas usados com sucesso para controlar a deterioração de frutas pós-colheita.

\begin{tabular}{|c|c|c|}
\hline ANTAGONISTA & PATÓGENO & FRUTA HOSPEDANTE \\
\hline \multicolumn{3}{|c|}{ Bactérias } \\
\hline Bacillus subtilis & $\begin{array}{c}\text { Botrytis cinerea } \\
\text { Penicillium digitatum } \\
\text { Colletotrichum gloesporioides }\end{array}$ & $\begin{array}{l}\text { Morango } \\
\text { Cítricos } \\
\text { Maçã }\end{array}$ \\
\hline $\begin{array}{c}\text { Enterobacter aerogenes } \\
\text { Enterobacter cloacae }\end{array}$ & $\begin{array}{l}\text { Alternaria alternata } \\
\text { Rhizopus stolonifer }\end{array}$ & $\begin{array}{l}\text { Cereja } \\
\text { Pêssego }\end{array}$ \\
\hline Pantoea agglomerans & $\begin{array}{c}\text { Penicillium digitatum } \\
\text { P. italicum } \\
\text { P. expansum }\end{array}$ & $\begin{array}{l}\text { Maçã } \\
\text { Maçã } \\
\text { Maçã }\end{array}$ \\
\hline $\begin{array}{l}\text { Pseudomonas fluorescens } \\
\text { Pseudomonas syringae }\end{array}$ & $\begin{array}{c}\text { Botrytis mali } \\
\text { Fusarium pallidoroseum } \\
\text { F. proliferatum }\end{array}$ & $\begin{array}{c}\text { Maçã } \\
\text { Banana } \\
\text { Banana }\end{array}$ \\
\hline \multicolumn{3}{|c|}{ Leveduras } \\
\hline $\begin{array}{l}\text { Candida oleophila } \\
\text { Candida sake }\end{array}$ & $\begin{array}{c}\text { Colletotrichium musae } \\
\text { Botrytis cinerea } \\
\text { Penicillium expansum } \\
\text { B. cinerea } \\
\text { P. expansum }\end{array}$ & $\begin{array}{l}\text { Banana } \\
\text { Maçã } \\
\text { Maçã } \\
\text { Uva } \\
\text { Uva }\end{array}$ \\
\hline Cryptococcus laurentii & Botrytis cinerea & Morango \\
\hline Kloeckera apiculata & $\begin{array}{l}\text { Botrytis cinerea } \\
\text { Penicillium spp. } \\
\text { P. digitatum } \\
\text { P. italicum } \\
\end{array}$ & $\begin{array}{l}\text { CerejaCítrica } \\
\text { Cítricos } \\
\text { Cítricos }\end{array}$ \\
\hline $\begin{array}{c}\text { Metschnikowia fructicola } \\
\text { Metschnikowia pulcherrima }\end{array}$ & $\begin{array}{c}\text { Botrytis cinerea } \\
\text { Penicillium expansum } \\
\text { P. digitatum } \\
\text { B. cinerea } \\
\text { P. expansum }\end{array}$ & $\begin{array}{c}\text { Uva } \\
\text { Maçã } \\
\text { Uva } \\
\text { Maçã } \\
\text { Maçã }\end{array}$ \\
\hline $\begin{array}{c}\text { Pichia anomala } \\
\text { Pichia guilliermondii }\end{array}$ & $\begin{array}{l}\text { Penicillium spp. } \\
\text { Botrytis cinerea }\end{array}$ & $\begin{array}{c}\text { Cítricos } \\
\text { Maçã e kiwi }\end{array}$ \\
\hline Rhodotorula mucilaginosa & Penicillium expansum & Pera \\
\hline \multicolumn{3}{|c|}{ Fungos filamentosos } \\
\hline Aureobasidium pullulans & $\begin{array}{l}\text { Monilinia laxa } \\
\text { Penicillium spp. } \\
\text { Botrytis cinerea }\end{array}$ & $\begin{array}{l}\text { Banana } \\
\text { Cítricos } \\
\text { Uva }\end{array}$ \\
\hline $\begin{array}{c}\text { Penicillium sp. (atenuado) } \\
\text { Penicillium frequentans }\end{array}$ & $\begin{array}{l}\text { Penicillium sp. } \\
\text { Monilinia sp. }\end{array}$ & $\begin{array}{l}\text { Abacaxi } \\
\text { Pêssego }\end{array}$ \\
\hline $\begin{array}{l}\text { Trichoderma harzianum } \\
\text { Trichoderma viride }\end{array}$ & $\begin{array}{c}\text { Colletotrichum musae } \\
\text { Botrytis cinerea } \\
\text { Botryodiplodia theobromae }\end{array}$ & $\begin{array}{c}\text { Maçã } \\
\text { Uva } \\
\text { Manga }\end{array}$ \\
\hline
\end{tabular}

Fontes; Sanisiewicz et al. (2000); Sharma et al. (2009). Adaptado por Martín Bonilla (2019).

\subsection{Perspectivas dos endófitos na pós-colheita.}

Droby et al. (2019), fizeram uma visão geral dos vários aspectos do uso de antagonistas microbianos como agentes de biocontrole na pós-colheita. Assim, ressaltam que identificar novos potenciais antagonistas, estudar os mecanismos delas na atividade de biocontrole e a influência dos parâmetros ambientais no crescimento e aptidão do biocontrole, servirá para a 
produção em massa de tecnologias ecológica na pós-colheita. Um exemplo a ser explorado como atividade antifúngica é a produção de lipopeptídeo C12-surfactina pelo o gênero Bacillus (Pang et al., 2021).

De forma geral, a caracterização ecológica de bactérias antagônicas associadas a diferentes estágios de desenvolvimento dos frutos pode representar uma visão promissora para o isolamento de novas populações com atividade de biocontrole. López-Gónzalez et al. (2021), descrevem que há uma abundância de espécies bacterianas antagônicas ao Penicillium expansum, e que elas são modificadas ao longo do desenvolvimento do fruto, sendo maior na fase de maturação.

A competição por espaço e nutrientes, supressão por sideróforos, enzimas hidrolíticas, antibiose, formação de biofilme e indução de resistência de plantas, são mecanismos que inibem o crescimento do fitopatógeno nos frutos apóscolheita. As espécies de Bacillus produtoras de metabólitos antifúngicos envolvidos na atividade antagonística produzem lipopeptídeos antifúngicos das famílias da iturina e da fengicina, que funcionam como alternativa de manutenção da qualidade e segurança do produto após-colheita (Carmona-Hernandez et al., 2019; López-Gónzalez et al., 2021).

A fim de explorar todo o potencial dos antagonistas microbianos, as pesquisas devem ter objetivos focados em compreender o mecanismo de inibição dos microrganismos, ter uma análise molecular da viabilidade microbiana, das condições de armazenamento no mercado, isto para escalar sua atividade em níveis industriais como tecnologia ecologicamente correta no futuro próximo (Silva-Jara et al., 2020). Na Tabela 3, são apresentados alguns microrganismos utilizados controle de doenças após colheita de frutas.

Tabela 3. Ingredientes ativos utilizados para biocontrole de deterioração em pós-colheita dos frutos.

\begin{tabular}{|c|c|c|}
\hline Ingrediente ativo & Fruta & Patógeno \\
\hline Pseudomonas syringae & Frutas de pomo, cítricas e morango. & $\begin{array}{c}\text { Penicillium, } \\
\text { Botrytis, } \\
\text { Mucor }\end{array}$ \\
\hline Bacillus subtilis & Abacate & $\begin{array}{c}\text { Cercospora, } \\
\text { Colletotrichum }\end{array}$ \\
\hline Pantoea agglomerans & Frutas de pomo, cítricos. & $\begin{array}{c}\text { Penicillium, } \\
\text { Botrytis, } \\
\text { Monilinia }\end{array}$ \\
\hline Candida sake & Frutas de pomo & $\begin{array}{c}\text { Penicillium, } \\
\text { Botrytis, } \\
\text { Rhizopus }\end{array}$ \\
\hline Candida oleophila & Botrytis, \\
& Frutas de pomo, cítricos, frutos de caroço e & $\begin{array}{c}\text { Penicillium, } \\
\text { Monilinia }\end{array}$ \\
\hline Candida oleophila & morangos. & $\begin{array}{c}\text { Botrytis, } \\
\text { Penicillium }\end{array}$ \\
\hline Cryptococcus albidus & Frutas de pomo & $\begin{array}{c}\text { Botrytis, } \\
\text { Penicillium, } \\
\text { Mucor }\end{array}$ \\
\hline Aureobasidium pullulans & Frutas de pomo & $\begin{array}{c}\text { Botrytis, } \\
\text { Penicillium, } \\
\text { Rhizopus, } \\
\text { Aspergillus }\end{array}$ \\
\hline & Frutas de pomo & $\begin{array}{c}\text { Penicillium, } \\
\text { Botrytis, } \\
\text { Monilinia }\end{array}$ \\
\hline
\end{tabular}

Fonte Dukare et al., (2019), adotado por Martín Bonilla (2019).

\section{Conclusões}

Os microrganismos endofíticos na atualidade se esta consolidando como uma tecnologia eficaz no controle de doenças. Portanto, com base nos resultados observados nas pesquisas consultadas, se faz as seguintes conclusões; 
$\checkmark$ A demanda global por alimentos mais saudáveis está em auge, pelo o controle de doenças através de microrganismo endofíticos é uma realidade na pós-colheita e é um desafio para as próximas pesquisas na obtenção de maiores benefícios ecológico.

$\checkmark$ Pela resistência de microrganismos aos produtos químicos, há interesse maior no biocontrole das doenças de frutas e hortaliças.

$\checkmark \quad \mathrm{O}$ consumidor ao ser muito mais exigente exige inocuidade no produto, pelo que os endofíticos surgem como alternativa de controle.

\section{Referências}

Abdelfattah, A., Wisniewski, M., Droby, S., \& Schena, L. (2016). Spatial and compositional variation in the fungal communities of organic and conventionally grown apple fruit at the consumer point-of-purchase. Horticulture research, 3(1), 1-12.

Benato, E. A. (1999). Controle de doenças pós-colheita em frutas tropicais. Summa Phytopathologica, 25(1), 90-93.

Benato, E. A. (2002). A indução de resistência no controle de doenças pós-colheita: frutas e hortaliças. Reunião Brasileira sobre Indução de Resistência em Plantas a Fitopatógenos, 1, 29-31.

Berendsen, R. L., Pieterse, C. M., \& Bakker, P. A. (2012). The rhizosphere microbiome and plant health. Trends in plant science, 17(8), 478-486.

Brito, T. S., de Lima, W. F., Pan, R., Porfirio, M. D., Canello, K. T., \& Chaves, E. I. D. O. (2018). Antagonismo de bactérias diazotróficas isoladas de plantas de milho no biocontrole de fitopatógenos. Revista Cultivando o Saber, 11(1), 78-88.

Carmona-Hernandez, S., Reyes-Pérez, J. J., Chiquito-Contreras, R. G., Rincon-Enriquez, G., Cerdan-Cabrera, C. R., \& Hernandez-Montiel, L. G. (2019). Biocontrol of postharvest fruit fungal diseases by bacterial antagonists: a review. Agronomy, 9(3), 121.

Chaouachi, M., Marzouk, T., Jallouli, S., Elkahoui, S., Gentzbittel, L., Ben, C., \& Djébali, N. (2021). Activity assessment of tomato endophytic bacteria bioactive compounds for the postharvest biocontrol of Botrytis cinerea. Postharvest Biology and Technology, $172,111389$.

Cia, P. (2002). Doenças de pós-colheita em frutos (Caqui, Maracujá-doce e Nêspera). Botucatu: Instituto de Tecnologia de Alimentos.

Coates, L., \& Johnson, G. (1997). Postharvest diseases of fruit and vegetables. Plant pathogens and plant diseases, 533-548.

Di Francesco, A., Martini, C., \& Mari, M. (2016). Biological control of postharvest diseases by microbial antagonists: how many mechanisms of action?. European Journal of Plant Pathology, 145(4), 711-717.

Droby, S., \& Wisniewski, M. (2018). The fruit microbiome: A new frontier for postharvest biocontrol and postharvest biology. Postharvest Biology and Technology, 140, 107-112.

Droby, S., Wisniewski, M., Macarisin, D., \& Wilson, C. (2009). Twenty years of postharvest biocontrol research: is it time for a new paradigm? Postharvest biology and technology, 52(2), 137-145.

Droby, S., Wisniewski, M., Teixidó, N., Spadaro, D., \& Jijakli, M. H. (2016). The science, development, and commercialization of postharvest biocontrol products. Postharvest Biology and Technology, 122, 22-29.

Droby, S., Wisniewski, M., Teixidó, N., Spadaro, D., \& Jijakli, M. H. (2019). Biocontrol of postharvest diseases with antagonistic microorganisms. In Postharvest Pathology of Fresh Horticultural Produce (pp. 463-498). CRC Press.

Dukare, A. S., Paul, S., Nambi, V. E., Gupta, R. K., Singh, R., Sharma, K., \& Vishwakarma, R. K. (2019). Exploitation of microbial antagonists for the control of postharvest diseases of fruits: a review. Critical reviews in food science and nutrition, 59(9), 1498-1513.

Huang, X., Ren, J., Li, P., Feng, S., Dong, P., \& Ren, M. (2021). Potential of microbial endophytes to enhance the resistance to postharvest diseases of fruit and vegetables. Journal of the Science of Food and Agriculture, 101(5), 1744-1757.

Janisiewicz, W. J., Tworkoski, T. J., \& Sharer, C. Y. N. T. H. I. A. (2000). Characterizing the mechanism of biological control of postharvest diseases on fruits with a simple method to study competition for nutrients. Phytopathology, 90(11), 1196-1200.

Kharwar, R. N., Sharma, V. K., Mishra, A., Kumar, J., Singh, D. K., Verma, S. K., \& Kusari, S. (2020). Harnessing the phytotherapeutic treasure troves of the ancient medicinal plant Azadirachta indica (Neem) and associated endophytic microorganisms. Planta medica.

Konsue, W., Dethoup, T., \& Limtong, S. (2020). Biological control of fruit rot and anthracnose of postharvest mango by antagonistic yeasts from economic crops leaves. Microorganisms, 8(3), 317.

Lastochkina, O., Baymiev, A., Shayahmetova, A., Garshina, D., Koryakov, I., Shpirnaya, I., \& Palamutoglu, R. (2020). Effects of endophytic Bacillus subtilis and salicylic acid on postharvest diseases (Phytophthora infestans, Fusarium oxysporum) development in stored potato tubers. Plants, 9(1), 76.

Liu, J., Sui, Y., Wisniewski, M., Droby, S., \& Liu, Y. (2013). Utilization of antagonistic yeasts to manage postharvest fungal diseases of fruit. International journal of food microbiology, 167(2), 153-160. 
López-González, R. C., Juárez-Campusano, Y. S., Rodríguez-Chávez, J. L., Delgado-Lamas, G., Medrano, S. M. A., Martínez-Peniche, R. Á., \& PachecoAguilar, J. R. (2021). Antagonistic activity of bacteria isolated from apple in different fruit development stages against blue mold caused by Penicillium expansum. The plant pathology journal, 37(1), 24.

Mariano, R. D. L. R., Da Silveira, E. B., de Assis, S. M. P., Gomes, A. M. A., Nascimento, A. R. P., \& Donato, V. M. T. S. (2004). Importância de bactérias promotoras de crescimento e de biocontrole de doenças de plantas para uma agricultura sustentável. Anais da Academia Pernambucana de Ciência Agronômica, 1, 89-111.

Martín Bonilla, C. (2019). Utilización de agentes de biocontrol para prevenir el deterioro de la fruta en poscosecha.

Medina-Romero, Y. M., Roque-Flores, G., \& Macías-Rubalcava, M. L. (2017). Volatile organic compounds from endophytic fungi as innovative postharvest control of Fusarium oxysporum in cherry tomato fruits. Applied microbiology and biotechnology, 101(22), 8209-8222.

Miguel, P. S. B., Delvaux, J. C., de Oliveira, M. N. V., de Camargo, R., Franco, M. H. R., de Araujo Sobreira, H., \& Jardim, V. H. P. (2021). Bactérias endofíticas: Colonização, benefícios e identificação. Brazilian Journal of Development, 7(1), 8777-8791.

Morales-Cedeño, L. R., del Carmen Orozco-Mosqueda, M., Loeza-Lara, P. D., Parra-Cota, F. I., de Los Santos-Villalobos, S., \& Santoyo, G. (2020). Plant growth-promoting bacterial endophytes as biocontrol agents of pre-and post-harvest diseases: Fundamentals, methods of application and future perspectives. Microbiological Research, 126612.

Pang, L., Xia, B., Liu, X., Yi, Y., Jiang, L., Chen, C., \& Wang, R. (2021). Improvement of antifungal activity of a culture filtrate of endophytic Bacillus amyloliquefaciens isolated from kiwifruit and its effect on postharvest quality of kiwifruit. Journal of Food Biochemistry, 45(1), e13551.

Peixoto, P. A. N. S., De Azevedo, J. L., \& Caetano, L. C. (2004). Microrganismos endofíticos em plantas: status atual e perspectivas. Boletin Latinoamericano y del Caribe de Plantas Medicinales y aromáticas, 3(4), 69-72.

Polli, A., Neves, A. F. D., Gallo, F., Gazarini, J., Rhoden, S. A., \& Pamphile, J. A. (2012). Aspectos da interação dos microrganismos endofíticos com plantas hospedeiras e sua aplicação no controle biológico de pragas na agricultura. SaBios-Revista de Saúde e Biologia, 7(2).

Rezende, C. C., Silva, M. A., de Mello Frasca, L. L., Faria, D. R., de Filippi, M. C. C., Lanna, A. C., \& Nascente, A. S. (2021). Microrganismos multifuncionais: utilização na agricultura. Research, Society and Development, 10(2), e50810212725-e50810212725.

Rhoden, S. A., Lucas, A. P. C., Evangelista, C. L., de Lima, F. S., de Carvalho Deprá, I., Nascimento, R. A., \& Pamphile, J. A. (2019). Aspectos Físicos, Químicos e Genéticos na Interação Patógeno Planta Hospedeira. SaBios-Revista de Saúde e Biologia, 14(1), 34-41.

Ribeiro, V. P., Almeida, C. N. S., gomes, E., LANA, U. D. P., marriel, I., \& oliveira-paiva, C. A. (2015). Efeito da inoculação de bactérias endofíticas solubilizadoras de fosfato sobre o crescimento de milheto (Pennisetum glaucum) fertilizado com fosfato de rocha. In Embrapa Milho e Sorgo-Artigo em anais de congresso (ALICE). In: congresso brasileiro de ciência do solo, 35., 2015, Natal. O solo e suas múltiplas funções: anais. Natal: Sociedade Brasileira de Ciência do Solo, 2015.

Santos, M. P., \& Girardello, R. (2021). Compostos com atividade antimicrobiana extraídos de microrganismos endofíticos isolados do bioma brasileiro. Revista Multidisciplinar em Saúde, 2(2), 55-55.

Santos, T. T., \& Varavallo, M. A. (2011). Aplicação de microrganismos endofíticos na agricultura e na produção de substâncias de interesse econômico. Semina: Ciências Biológicas e da Saúde, 32(2), 199-212.

Senhor, R. F., De Souza, P. A., Neto, R. C. A., Maracajá, P. B., \& do Nascimento, F. J. (2009). Manejo de doenças pós-colheita. Revista Verde de agroecologia e desenvolvimento sustentável, $4(1), 1$.

Sharma, R. R., Singh, D., \& Singh, R. (2009). Biological control of postharvest diseases of fruits and vegetables by microbial antagonists: A review. Biological control, 50(3), 205-221.

Silva, H. S. A., da Silva Romeiro, R., Macagnan, D., de Almeida Halfeld-Vieira, B., Pereira, M. C. B., \& Mounteer, A. (2004). Rhizobacterial induction of systemic resistance in tomato plants: non-specific protection and increase in enzyme activities. Biological Control, 29(2), 288-295.

Silva, M. A., Nascente, A. S., Filippi, M. C. C. D., Lanna, A. C., Silva, G. B. D., \& Silva, J. F. A. E. (2020). Microrganismos promotores de crescimento isolados e combinados afetando a produção de biomassa, trocas gasosas e o conteúdo de nutrientes em plantas de soja. Revista Caatinga, 33(3), 619-632.

Silva-Jara, J. M., López-Cruz, R., Ragazzo-Sánchez, J. A., \& Calderón-Santoyo, M. (2020). Antagonistic microorganisms efficiency to suppress damage caused by Colletotrichum gloeosporioides in papaya crop: Perspectives and challenges. Revista Mexicana de Ingeniería Química, 19(2), 839-849.

Spadaro, D., \& Droby, S. (2016). Development of biocontrol products for postharvest diseases of fruit: the importance of elucidating the mechanisms of action of yeast antagonists. Trends in Food Science \& Technology, 47, 39-49.

Strobel, G., Daisy, B., Castillo, U., \& Harper, J. (2004). Natural products from endophytic microorganisms. Journal of Natural products, 67(2), 257-268.

Ungaratti, A., Gomes, R., \& Vieira, J. (2020). Enzimas de interesse comercial isoladas de bactérias endofíticas da erva-daninha Tridax procumbens (L.)(ervade-touro). Enciclopédia biosfera, 17(34).

Zhimo, V. Y., Bhutia, D. D., \& Saha, J. (2016). Biological control of post harvest fruit diseases using antagonistic yeasts in India. Journal of Plant Pathology, $275-283$. 